\title{
Diagnostic value of hepatic artery perfusion fraction combined with TGF- $\beta$ in patients with hepatocellular carcinoma
}

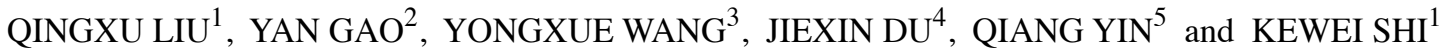 \\ ${ }^{1}$ Department of Medical Imaging, Affiliated Hospital of Jining Medical University, Jining, Shandong 272000; \\ ${ }^{2}$ Department of Radiology, People's Hospital of Rizhao, Rizhao, Shandong 276800; \\ Departments of ${ }^{3}$ Medical Records and ${ }^{4}$ Neurology, The People's Hospital of Zhangqiu Area, Jinan, Shandong 250200; \\ ${ }^{5}$ Ward 1, Department of Oncology, People's Hospital of Rizhao, Rizhao, Shandong 276800, P.R. China
}

Received November 20, 2018; Accepted March 21, 2019

DOI: $10.3892 / 01.2019 .10228$

\begin{abstract}
Diagnostic value of hepatic artery perfusion fraction (HAF) combined with transforming growth factor- $\beta$ (TGF- $\beta$ ) in the diagnosis of primary liver carcinoma (PLC) was evaluated. The clinical data of 128 PLC patients undergoing radical hepatectomy in Affiliated Hospital of Jining Medical University were regarded as the study group. Seventy-four healthy volunteers examined in Affiliated Hospital of Jining Medical University were collected as the control group. Double-antibody sandwich enzyme-linked immunosorbent assay was used to detect the expression level of serum TGF- $\beta$. The upper abdomen of the subjects was scanned by a 64 -slice spiral CT, and the perfusion parameters were analyzed and calculated. According to the HAF and the expression level of TGF- $\beta$ in the two groups, single and combined detection of TGF- $\beta$ and HAF parameters were detected, respectively, by ROC curve. The expression of TGF- $\beta$ in serum of the study group was higher than that of the control group $(\mathrm{P}<0.05)$. The expression level of serum TGF- $\beta$ was closely related to total bilirubin, ascites, TNM stage, prothrombin time and tumor diameter. Blood flow (BF), blood volume (BV), permeability surface (PS), HAF and other perfusion parameters in the study group were higher than those in the control group $(\mathrm{P}<0.05)$. The specificity and sensitivity of TGF- $\beta$ expression level in diagnosing PLC were 73 and 93\%, respectively; the specificity and sensitivity of HAF parameter in diagnosing PLC were 73 and $100 \%$, respectively; the specificity and sensitivity of HAF parameter combined with TGF- $\beta$ expression level were 84 and $100 \%$, respectively. TGF- $\beta$ is highly expressed in serum of PLC patients; HAF parameter combined with TGF- $\beta$ expression level can improve the specificity and has an important
\end{abstract}

Correspondence to: Dr Kewei Shi, Department of Medical Imaging, Affiliated Hospital of Jining Medical University, 89 Guhuai Road, Jining, Shandong 272000, P.R. China

E-mail:k6q6pq@163.com

Key words: CT perfusion imaging, TGF- $\beta$, primary liver carcinoma, hepatic artery perfusion fraction, diagnostic value value in the diagnosis of PLC, which is worthy of clinical promotion.

\section{Introduction}

Primary liver carcinoma (PLC) is one of the most common malignant tumors in the world with high morbidity and mortality, ranking sixth in the incidence of malignant tumors and second in the mortality rate (1). The incidence of PLC is increasing year by year. According to the World Health Organization (WHO), there will be 1.3413 million patients with liver cancer in the world by 2034, accounting for about $7 \%$ of all cancer patients (2). The onset of PLC is obscure, and the early stage of cancer often lacks specific clinical features and signs, which are difficult for patients to detect. Moreover, PLC has a high malignant degree, fast spread of cancer cells and strong invasiveness. Obvious symptoms often occur in the advanced and terminate stages of cancer, at which time the treatment effect is poor (3). Up to now, the etiology of PLC is not completely clear, but some studies suggest that chronic infectious diseases such as hepatitis B, C-type virus, and living habits such as smoking, drinking are risk factors of PLC (4). At present, with the development of medical technology, the treatment of PLC has greatly improved, but the therapeutic effect is not satisfactory. Studies have shown that the cure rate of liver cancer patients in Shanghai is only $11.72 \%$, and the 5-year survival rate is only $15.45 \%$ (5), indicating that liver cancer causes great harm to the health and safety of humans. Some studies suggest that early diagnosis and treatment can improve the prognosis and survival rate of patients with PLC (6). Therefore, finding a more accurate and convenient way to diagnose PLC is of great importance to medical scientists.

The commonly used serum marker of PLC is alpha fetoprotein (AFP), but some studies have suggested that it is less sensitive and has some limitations on the diagnosis of PLC (7). Transforming growth factor- $\beta$ (TGF- $\beta$ ), a multifunctional cytokine, is located on chromosome $19 \mathrm{q} 13$, composed of seven exons, and mainly produced by stellate cells (8). It plays a variety of physiological roles in the body, which can regulate cell migration, proliferation, the formation of external mechanisms, but also promote wound healing and scar reduction (9). 
TGF- $\beta$ has a strong inhibitory effect on the cellular immune function of the body. In the occurrence and development of tumor cells, it can promote the growth of tumor cells by inhibiting immune cells, and has a tumor-promoting effect (10). Some studies have shown that serum TGF- $\beta$ has a high level in patients with non-small cell lung cancer, and TGF- $\beta$ is a valuable tumor biomarker with the decrease of its level after chemotherapy (11).

Magnetic resonance imaging (MRI), Doppler ultrasound, digital subtraction angiography and CT are commonly used to diagnose PLC (12). MRI is expensive and time-consuming, which can be a great economic burden for patients (13). Doppler ultrasound has high technical requirements for operators, and the detection often has many blind spots because of tissue overlap, so it has some limitations in the disease detection (14). At present, CT perfusion imaging is well developed, and the latest CT perfusion imaging provides a more accurate, clear and stable imaging basis for clinical detection. It can detect the characterization, localization and staging of cancer in detail and show the location and size of the tumor, and it is also easy to operate and popularize (15). CT perfusion imaging reflects changes in the concentration of contrast medium per voxel or pixel in unit time, promoting the rapid diagnosis of diseases. Its mathematical model can detect the tissues and organs in a simple and direct way, and can provide very valuable diagnostic information (16).

At present, there are few studies on the early diagnosis of PLC. Therefore, the diagnostic and differential value of CT perfusion parameters combined with serum TGF- $\beta$ in PLC was analyzed in this study to find an accurate and convenient diagnostic method for PLC, and to provide reference for clinical practice.

\section{Patients and methods}

General information. The clinical data of 128 PLC patients undergoing radical hepatectomy in Affiliated Hospital of Jining Medical University (Jining, China) were regarded as the study group, including 79 males and 49 females, with an average range of $50.49 \pm 16.90$ years. All patients in this group were pathologically confirmed as PLC by surgical operation or puncture biopsy in the Affiliated Hospital of Jining Medical University. At the same time, 74 healthy volunteers examined were collected as the control group, including 44 males and 30 females, with an average age of $51.83 \pm 15.48$ years. All the patients signed an informed consent form. The study was approved by the Ethics Committee of Affiliated Hospital of Jining Medical University.

Inclusion and exclusion criteria. Inclusion criteria were: Patients admitted to Affiliated Hospital of Jining Medical University, aged 20-70; patients with complete clinical records or medical examination data; patients receiving no radiotherapy, chemotherapy or radiofrequency ablation prior to admission.

Exclusion criteria were: Patients admitted to hospital for relapse; patients with severe heart, cerebrovascular and other diseases; patients with diabetes, renal dysfunction, hyperthyroidism and other malignant diseases; patients with a history of organ transplantation.
Main reagents and instruments. Spiral CT machine (64-slice) (GE Healthcare, Chicago, IL, USA, model: light speed VCT); TGF- $\beta$ ELISA kit (Nanjing Jin Yibai Biotechnology Co., Ltd., Nanjing, China, cat. no. JEB-11723); automatic quantitative microplate reader (Anthos Labtec Instruments $\mathrm{GmbH}$, Salzburg, Austria, model: anthos2010); UV-vis spectrophotometer (Shanghai Runqee instrument Technology Co., Ltd., Shanghai, China, model: UV1700).

Serum collection. After fasting for more than $8 \mathrm{~h}, 6 \mathrm{ml}$ of external cubital vein blood was drawn from all participants in the morning, placed in vacuum vessels and stored in a refrigerator. The samples were taken out and placed at room temperature for approximately $30 \mathrm{~min}$, then centrifuged at $3,000 \mathrm{x}$ g for $15-20 \mathrm{~min}$ at $4^{\circ} \mathrm{C}$ to separate serum. After centrifugation, a transferpettor (Thermo Fisher Scientific, Inc., Waltham, MA, USA) was carefully used to absorb $350 \mu \mathrm{l}$ of the supernatant. It was placed in four EP tubes, frozen in liquid nitrogen and stored at $-80^{\circ} \mathrm{C}$ for further detection. All of the above operations were carried out in an aseptic environment.

Detection methods of TGF- $\beta$. The expression of serum TGF- $\beta$ in the study group and the control group was detected by double-antibody sandwich enzyme-linked immunosorbent assay (ELISA).

The sample to be tested and the kit were removed from the refrigerator and re-melted at room temperature of $30^{\circ} \mathrm{C}$. The enzyme label plate was taken out; $50 \mu \mathrm{l}$ of the standard sample was poured into the standard sample well; $10 \mu \mathrm{l}$ of the sample to be tested and $40 \mu \mathrm{l}$ of the sample diluent were added to the sample; and $100 \mu \mathrm{l}$ of chromogenic antibody was added to each well except the blank wells. After $60 \mathrm{~min}$ of water bath at $37^{\circ} \mathrm{C}$, the enzyme label plate was removed, and $50 \mu \mathrm{l}$ of washing liquid was added into each well. After standing for $1 \mathrm{~min}$, the liquid in the wells was dried, and the plate was washed 5 times. Enzyme (50 $\mu \mathrm{l})$ label solution was added into each well (except the blank control well). After 15 min of water bath in a vibrating flume (Bio-Rad Laboratories, Inc., Hercules, CA, USA) at $37^{\circ} \mathrm{C}$, chromogenic agent was added for visualizing in the dark for $15 \mathrm{~min}$. The enzyme label plate was removed and the reaction was stopped by termination solution. The absorbance of each well was measured at the wavelength of $450 \mathrm{~nm} 10 \mathrm{~min}$ following termination. The ratio of it to sample absorbance was calculated according to the absorbance value corresponding to the concentration of standard sample, and when the ratio was $>99 \%$, the product was qualified. The linear regression equation was calculated by an automatic microplate reader, and the sample concentration was calculated according to the absorbance measured.

CT scanning methods. All subjects were required to fast for $8 \mathrm{~h}$ before examination, and $1000 \mathrm{ml}$ of warm water was administered $20 \mathrm{~min}$ before CT scanning to fill the stomach, small intestine and duodenum. Before entering the CT room, the primary nurse explained the examination process and precautions in detail to obtain the patients full co-operation, and eliminate their uneasiness, training them to inhale, exhale and hold their breath according to the instrument's voice prompts, to achieve a smooth scan. Subjects took the supine position and raised their hands to 
Table I. Comparison of general baseline information between the two groups [n (\%)] (mean \pm SD).

\begin{tabular}{|c|c|c|c|c|}
\hline Classification & Study group $(n=128)$ & Control group $(\mathrm{n}=74)$ & $\chi^{2} / \mathrm{t}$ value & P-value \\
\hline Age & $50.49 \pm 16.90$ & $51.83 \pm 15.48$ & 0.560 & 0.576 \\
\hline Sex & & & 0.101 & 0.767 \\
\hline Male & 79 (61.72) & $44(59.46)$ & & \\
\hline Female & $49(38.28)$ & $30(40.54)$ & & \\
\hline $\operatorname{BMI}\left(\mathrm{kg} / \mathrm{m}^{2}\right)$ & & & 0.320 & 0.629 \\
\hline$<24$ & $93(72.66)$ & $51(68.92)$ & & \\
\hline$\geq 24$ & $35(27.34)$ & $23(31.08)$ & & \\
\hline Heart rate (time/min) & & & 1.588 & 0.262 \\
\hline$<60$ & $18(14.06)$ & $11(14.86)$ & & \\
\hline$\geq 60$ & $110(85.94)$ & $63(85.14)$ & & \\
\hline Renal function & & & 0.283 & 0.603 \\
\hline Normal & $101(78.91)$ & $56(75.68)$ & & \\
\hline Abnormal & $27(21.09)$ & $18(24.32)$ & & \\
\hline Serum creatinine $(\mu \mathrm{mol} / \mathrm{l})$ & & & 0.098 & 0.833 \\
\hline$<133$ & $17(13.28)$ & $9(12.16)$ & & \\
\hline$\geq 133$ & $111(86.72)$ & $65(87.84)$ & & \\
\hline Smoking & & & 0.199 & 0.763 \\
\hline$<$ Yes & $79(61.72)$ & $48(64.86)$ & & \\
\hline$\geq \mathrm{No}$ & $49(38.28)$ & $26(35.14)$ & & \\
\hline Fasting blood sugar $(\mathrm{mmol} / \mathrm{l})$ & $4.71 \pm 0.68$ & $4.64 \pm 0.78$ & 0.668 & 0.505 \\
\hline $\mathrm{Hb}(\mathrm{g} / \mathrm{l})$ & $127.18 \pm 16.93$ & $126.17 \pm 15.99$ & 0.417 & 0.677 \\
\hline $\mathrm{RBC}\left(\mathrm{x} 10^{12} / \mathrm{l}\right)$ & $4.63 \pm 0.31$ & $4.59 \pm 0.42$ & 0.774 & 0.440 \\
\hline $\operatorname{PLT}\left(\mathrm{x} 10^{9} / \mathrm{l}\right)$ & $213.85 \pm 54.86$ & $218.09 \pm 51.85$ & 0.540 & 0.580 \\
\hline
\end{tabular}

reduce the scanning artifacts. The scanning ranged from diaphragm level to inferior pole of the kidneys. Obvious solid enhancement areas of the patients in the study group were scanned, with tube voltage of $120 \mathrm{kV}$, automatic millisecond tube current, rotational speed of $0.8 \mathrm{sec} /$ rotation, pitch of 0.984 , section thickness and intersection gap of $5 \mathrm{~mm}$ and detector collimation of $64 \times 0.625$, for routine plain scan of the liver. Rapid injection and dynamic scanning were performed when necessary, and image analysis and measurement were conducted by our senior image analysts. The computer software automatically calculated and displayed the corresponding perfusion parameters: blood flow (BF), blood volume (BV), permeability surface (PS), mean transit time (MTT), hepatic artery perfusion fraction (HAF).

Statistical analysis. Statistical analysis was carried out by using SPSS17.0 software (Beijing Strong Vinda Information Technology Co., Ltd., Beijing, China). The expression of TGF- $\beta$ was expressed as mean \pm standard deviation (mean $\pm \mathrm{SD}$ ). A t-test was used to compare the measurement data among groups, and Chi-square test was used to compare the enumeration data among groups. The receiver operating characteristic (ROC) curve was used to evaluate the diagnostic efficacy of serum TGF- $\beta$ expression combined with $\mathrm{CT}$ test data. $\mathrm{P}<0.05$ was considered to indicate a statistically significant difference.

\section{Results}

General baseline information. There was no statistically significant difference in age, sex, body mass index (BMI), heart rate, renal function, serum creatinine, smoking, fasting blood sugar, hemoglobin (HB), red blood cell (RBC), platelet (PLT) between the study group and the control group $(\mathrm{P}>0.05)$ (Table I).

Comparison of serum TGF- $\beta$ expression between the study and control groups. Results of ELISA analysis showed that the expression of TGF- $\beta$ in serum of the study group $(236.46 \pm 75.83)$ was higher than that of the control group $(144.34 \pm 32.64)$, and the difference was statistically significant $(\mathrm{t}=9.924, \mathrm{P}<0.01)$ (Fig. 1).

Relationship between TGF- $\beta$ expression and clinicopathology in the study group. Results of ELISA detection showed that the expression level of serum TGF- $\beta$ in the study group was associated with total bilirubin, ascites, TNM stage, prothrombin time, tumor diameter, lymph node metastasis and distant metastasis, and the difference was statistically significant $(\mathrm{P}<0.05)$ (Table II).

Comparison of CT perfusion parameters between the study group and control group. The results 
Table II. Comparison of serum TGF- $\beta$ expression with clinicopathology in the study group (mean \pm SD).

\begin{tabular}{|c|c|c|c|c|}
\hline Classification & Study group $(\mathrm{n}=128)$ & TGF- $\beta$ (ng/l) & $\mathrm{t}$ value & P-value \\
\hline Total bilirubin $(\mu \mathrm{mol} / \mathrm{l})$ & & & 3.568 & $<0.01$ \\
\hline$<33$ & 42 & $219.44 \pm 58.81$ & & \\
\hline$\geq 33$ & 86 & $257.25 \pm 55.04$ & & \\
\hline Ascites & & & 7.922 & $<0.01$ \\
\hline Yes & 63 & $279.43 \pm 32.86$ & & \\
\hline No & 65 & $215.69 \pm 55.06$ & & \\
\hline Prothrombin time (sec) & & & 7.360 & $<0.01$ \\
\hline$<14$ & 16 & $195.03 \pm 34.40$ & & \\
\hline$\geq 14$ & 112 & $272.36 \pm 39.93$ & & \\
\hline Tumor diameter & & & 6.612 & $<0.01$ \\
\hline$<5 \mathrm{~cm}$ & 47 & $216.35 \pm 55.72$ & & \\
\hline$\geq 5 \mathrm{~cm}$ & 81 & $272.45 \pm 39.84$ & & \\
\hline TNM stage & & & 8.920 & $<0.01$ \\
\hline I-II & 59 & $202.59 \pm 41.96$ & & \\
\hline III-IV & 69 & $269.59 \pm 42.70$ & & \\
\hline Lymph node metastasis & & & 4.911 & $<0.01$ \\
\hline Yes & 35 & $281.58 \pm 30.71$ & & \\
\hline No & 93 & $225.45 \pm 64.82$ & & \\
\hline Distant metastasis & & & 5.866 & $<0.01$ \\
\hline Yes & 38 & $282.32 \pm 29.97$ & & \\
\hline No & 90 & $221.45 \pm 60.82$ & & \\
\hline
\end{tabular}

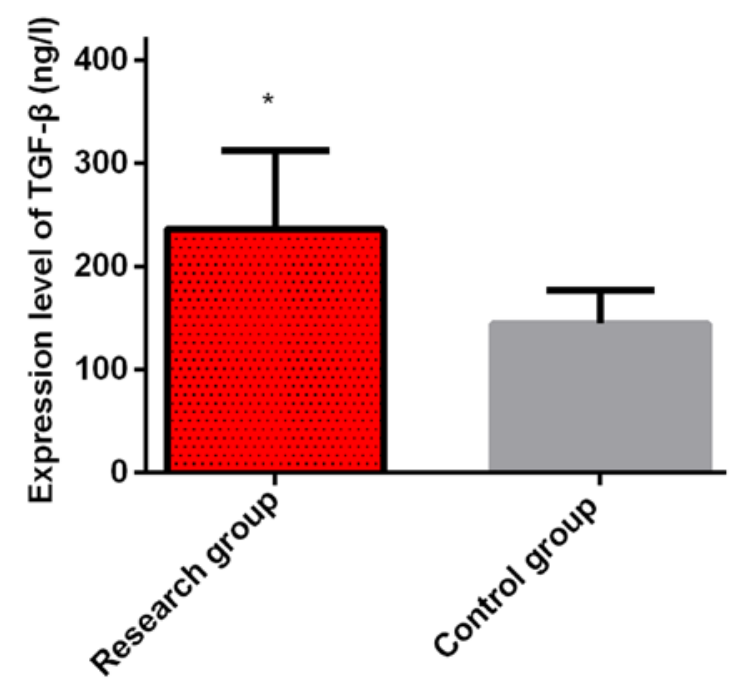

Figure 1. Comparison of serum TGF- $\beta$ expression between the study group and the control group. Results of ELISA detection found that the expression of TGF- $\beta$ in serum of the study group was higher than that of the control group, the difference was statistically significant $(\mathrm{t}=9.924$, $\mathrm{P}<0.01)$. ${ }^{*}$ Compared with the control group, the difference was statistically significant.

showed that, the BF parameter in the study group $(212.45 \pm 42.34 \mathrm{ml} / \mathrm{min} / 100 \mathrm{~g})$ was higher than that in the control group $(128.35 \pm 24.59 \mathrm{ml} / \mathrm{min} / 100 \mathrm{~g})$, with statistical difference $(\mathrm{t}=15.620, \mathrm{P}<0.01)$; the $\mathrm{BV}$ parameter in the study group $(41.83 \pm 10.2 \mathrm{ml} / 100 \mathrm{~g})$ was higher than that in the control group $(28.86 \pm 7.53 \mathrm{ml} / 100 \mathrm{~g})$, with statistical difference $(\mathrm{t}=9.514, \mathrm{P}<0.01)$; there was no statistical difference in the MTT parameter between the study group $(9.43 \pm 4.39 \mathrm{sec})$ and the control group $(10.83 \pm 5.82 \mathrm{sec})(\mathrm{t}=1.933, \mathrm{P}=0.055)$; the PS parameter in the study group $(27.42 \pm 9.33 \mathrm{ml} / \mathrm{min} / 100 \mathrm{~g})$ was higher than that in the control group $(19.45 \pm 7.35 \mathrm{ml} / \mathrm{min} / 100 \mathrm{~g})$, with statistical difference $(\mathrm{t}=6.302, \mathrm{P}<0.01)$; the HAF parameter in the study group $(0.63 \pm 0.15)$ was higher than that in the control group $(0.44 \pm 0.09)$, with statistical difference $(\mathrm{t}=30.77, \mathrm{P}<0.01)$ (Fig. 2).

Diagnostic value of HAF parameter and TGF- $\beta$ expression in PLC. The HAF parameter and TGF- $\beta$ expression in the study and control groups were plotted as ROC curve of PLC diagnosis. The results showed that the AUC value of TGF- $\beta$ expression in PLC was 0.8699 (95\% CI: 0.8221-0.9178); the specificity was $73 \%$; the sensitivity was $93 \%$, and the best cut-off point was $191.30 \mathrm{ng} / \mathrm{l}$. The AUC value of $\mathrm{HAF}$ parameter in PLC was 0.8858 (95\% CI: 0.8364-0.9352); the specificity was $73 \%$; the sensitivity was $100 \%$, and the best cut-off point was 0.5150 . Logistic regression analysis was used to analyzed the expression level of TGF- $\beta$ and HAF parameter in the two groups, and the further combination of regression data with HAF parameter and TGF- $\beta$ expression to draw the ROC curve for PLC diagnosis. The results showed that the AUC value of HAF parameter combined with TGF- $\beta$ expression in PLC was 0.9277 (95\% CI: 0.8892-0.9662); the specificity was $84 \%$; the sensitivity was $100 \%$, and the best cut-off point was 0.3098 (Fig. 3). 


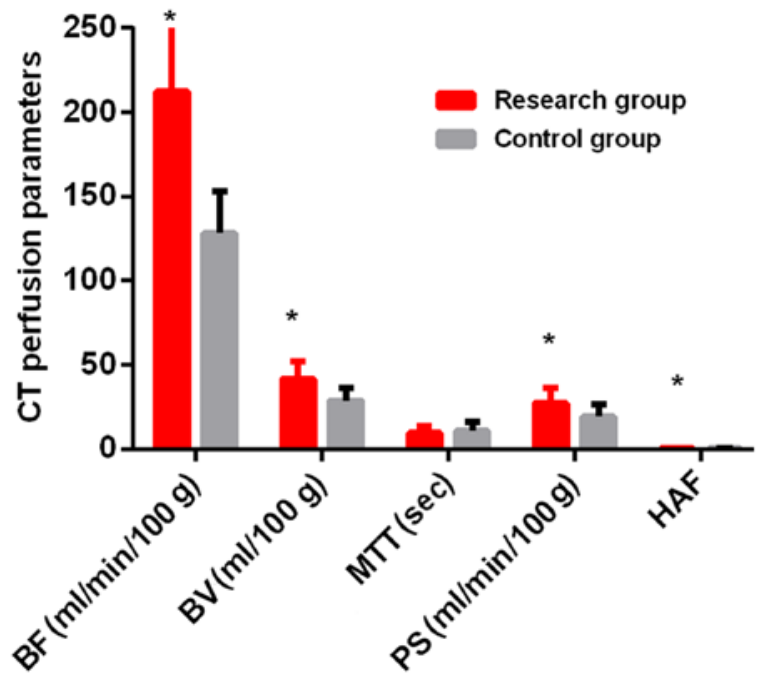

Figure 2. Comparison of CT perfusion parameters between the study group and the control group. The results of 64-slice spiral CT showed that, the $\mathrm{BF}$ parameter in the study group was higher than that in the control group, with statistical difference $(\mathrm{t}=15.620, \mathrm{P}<0.01)$; the $\mathrm{BV}$ parameter in the study group was higher than that in the control group, with statistical difference $(\mathrm{t}=9.514, \mathrm{P}<0.01)$; there was no statistical difference in the MTT parameter between the study group and the control group $(\mathrm{t}=1.933, \mathrm{P}=0.055)$; the PS parameter in the study group was higher than that in the control group, with statistical difference $(\mathrm{t}=6.302, \mathrm{P}<0.01)$; the HAF parameter in the study group was higher than that in the control group, with statistical difference $(\mathrm{t}=30.77, \mathrm{P}<0.01)$. ${ }^{*}$ Compared with the control group, the difference was statistically significant.

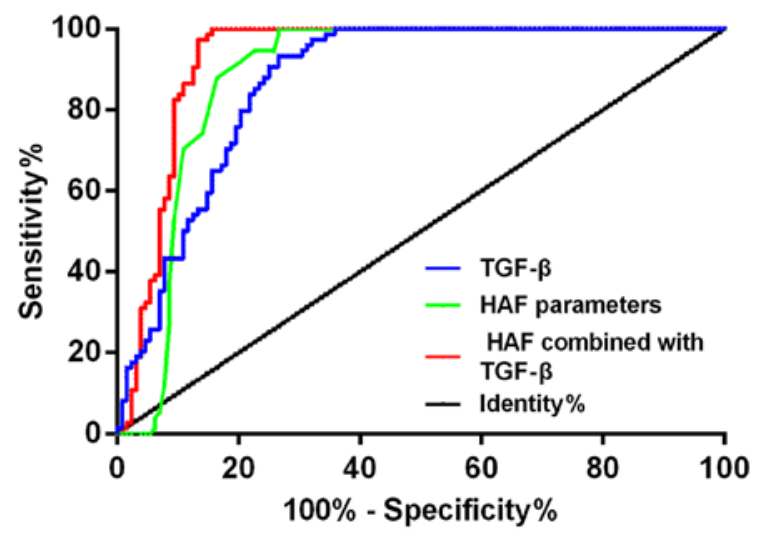

Figure 3. Diagnostic value of HAF parameter and TGF- $\beta$ expression in PLC The AUC value of TGF- $\beta$ expression in PLC was 0.8699 (95\% CI: $0.8221-0.9178$ ), the specificity was $73 \%$, the sensitivity was $93 \%$, and the best cut-off point was $191.30 \mathrm{ng} / \mathrm{l}$. The AUC value of HAF parameter in PLC was 0.8858 (95\% CI: $0.8364-0.9352)$, the specificity was $73 \%$, the sensitivity was $100 \%$, and the best cut-off point was 0.5150 . The AUC value of HAF parameter combined with TGF- $\beta$ expression in PLC was 0.9277 (95\% CI: $0.8892-0.9662$ ), the specificity was $84 \%$, the sensitivity was $100 \%$, and the best cut-off point was 0.3098 .

\section{Discussion}

The liver is an important immunologically privileged organ and plays an important role in the immune regulation of the body. PCL is a very common malignant tumor of the liver with a high mortality rate, second only to lung cancer. The mortality rate is increasing gradually because of late diagnosis and insufficient treatment regimen causing threat to patients' health and quality of life (17). There are no obvious symptoms in the early stage of PLC, which to a large extent increases the difficulty of accurate diagnosis of PLC in the early clinical stage. The vast majority of patients have advanced cancer when they develop symptoms such as liver pain, jaundice, ascites, stiffness, lethargy and other symptoms, losing the opportunities for thorough treatment such as radical resection of liver cancer (18). The occurrence of PLC is related to many factors, such as hepatitis B virus, hepatitis A virus, alcoholism, fatty liver, smoking or inherited. It is impossible to establish an effective preventive measure against PLC in a short time (19), but early discovery and treatment can often improve the therapeutic efficacy, prognosis and survival time of patients. Therefore, many scholars are working to find a more accurate and sensitive diagnostic method for the treatment of PLC.

TGF- $\beta$, a multifunctional cell growth factor, has a molecular weight of approximately $12.5 \mathrm{kDa}$, and its biological function is mainly in inflammation, embryonic development, and tissue repair. It has been found that TGF- $\beta$ plays an important role in regulating cell differentiation, proliferation, apoptosis and immune function. Moreover, it can inhibit immune cells and stimulate the proliferation of extracellular matrix (20). The expression of TGF- $\beta$ is increased to varying degrees in a variety of malignant tumors, indicating that TGF- $\beta$ is of great significance in the occurrence and development of tumors (21). Some studies have shown that the expression of TGF- $\beta$ in hepatitis $B$ virus carriers is higher than that in healthy persons (22). The expression level of TGF- $\beta$ is closely related to the invasion and metastasis of PLC and can change the microenvironment of a tumor and increase the possibility of tumor invasion and metastasis, and it is also an independent prognostic factor of PLC (23). Song et al (24) used TGF- $\beta$ and AFP to diagnose PLC, and the results suggested that TGF- $\beta$ may be a useful serum marker for early detection of PLC, because compared with AFP, TGF- $\beta$ is more sensitive in the diagnosis of PLC.

CT perfusion scan, based on CT plain scan, can show the lesion completely and intuitively and calculate various CT perfusion parameters by using different mathematical models, which can effectively reflect the changes of local tissue perfusion volume (25). BV refers to the blood volume in the tissue vascular structure, whose perfusion parameters are affected by the size of the blood vessel and the number of capillaries opening. A large number of immature neovascularization in tumors and the increase of blood flow through abnormal blood vessels can lead to the increase of $\mathrm{BV}$ value. $\mathrm{BF}$ is the volume of blood flowing through liver tissue per unit of time. Due to the random growth of tumors, the volume of blood flowing through the liver tissue per unit time increases, resulting in an increase in the BF value. HAF refers to the average fraction of the volume of blood flowing through the hepatic artery per unit time. Because PLC cancer cells are mainly blood supplied by hepatic artery and contain abundant capillaries, the increase of arterial blood component in PLC can break the proportion of blood supply, which leads to the rise of HAF. PS is the unidirectional transport flow rate of contrast agents from capillaries into the intercellular space. Because endothelial cells in the wall of the abnormal microvessels in a large number of tumor tissues in the liver are incomplete, contrast agents are easy to enter and exit blood vessels and tissue space, thereby, leading to increase of PS value (26). Since hepatic artery is the major 
blood supply for PLC cancer cells, and HAF can clearly reflect the blood flow of hepatic artery, HAF parameter is used as a diagnostic criterion for PLC.

Bilezikçi et al (27) considered that overexpression of TGF- $\beta$ may lead to the occurrence of liver cancer, which is similar to our results. The expression of TGF- $\beta$ in the serum of PLC patients and normal controls was compared in this study, and the results showed that the expression of TGF- $\beta$ in the serum of PLC patients was higher than that of normal controls, and the difference was statistically significant $(\mathrm{P}<0.05)$. Further study on the clinicopathological features and the expression of TGF- $\beta$ in patients with PLC found that the expression level of serum TGF- $\beta$ was related to total bilirubin, ascites, TNM stage, prothrombin time, tumor diameter, lymph node metastasis and distant metastasis $(\mathrm{P}<0.05)$, which is similar to the result of $\mathrm{Lu}$ et al (28). They studied the relationship between TGF- $\beta$ expression and PLC, and found that TGF- $\beta$ expression was closely related to metastasis, histological grading and penetration depth of PLC. The perfusion parameters of BF, $\mathrm{BV}, \mathrm{PS}, \mathrm{HAF}$ in PLC patients were higher than those in normal controls $(\mathrm{P}<0.05)$. The result is similar to that of $\mathrm{Li}$ et al (29) who considered that there were significant differences in perfusion parameters such as BF, BV, PS between normal liver tissues and hepatocellular carcinoma tissues. In our study, by drawing the ROC curve of HAF parameters and TGF- $\beta$ expression level in the diagnosis of PLC, it was found that the specificity and sensitivity of TGF- $\beta$ expression level in diagnosing PLC were $73 \%$ and $93 \%$, respectively; the specificity and sensitivity of HAF parameter in diagnosing PLC were 73 and $100 \%$, respectively; the specificity and sensitivity of HAF parameter combined with TGF- $\beta$ expression level were 84 and $100 \%$, respectively. The specificity and sensitivity of HAF parameter combined with TGF- $\beta$ expression in the diagnosis of PLC were higher than that of any single test, indicating that HAF parameter combined with TGF- $\beta$ expression has a higher diagnostic value for PLC.

The subjects enrolled in this study were selected strictly according to the inclusion and exclusion criteria to ensure the reliability of the results of this study. However, the number of patients was small, more PLC patients with different pathological types should be collected for a future study. The correlation between HAF parameter, TGF- $\beta$ expression and other clinical symptoms of PLC patients was not studied in depth, so some limitations may exist. Regular follow-up will be conducted.

In conclusion, TGF- $\beta$ is highly expressed in serum of PLC patients; the perfusion parameters of BF, BV, PS, HAF in PLC patients are higher than those in normal controls; the expression level of TGF- $\beta$ is related to total bilirubin, ascites, TNM stage, prothrombin time, tumor diameter, lymph node metastasis and distant metastasis; HAF parameter combined with TGF- $\beta$ expression level can improve the specificity and sensitivity and has an important value in the diagnosis of PLC.

\section{Acknowledgements}

Not applicable.

\section{Funding}

No funding was received.

\section{Availability of data and materials}

The datasets used and/or analyzed during the present study are available from the corresponding author on reasonable request.

\section{Authors' contributions}

QL drafted the manuscript. QL and YG performed ELISA. YW and JD collected the patients' general data. QY and KS analyzed CT results. All authors read and approved the final manuscript.

\section{Ethics approval and consent to participate}

The study was approved by the Ethics Committee of Affiliated Hospital of Jining Medical University (Jining, China). Patients who participated in this research had complete clinical data. Signed informed consents were obtained from the patients or the guardians.

\section{Patient consent for publication}

Not applicable.

\section{Competing interests}

The authors declare that they have no competing interests.

\section{References}

1. Valery PC, Laversanne M, Clark PJ, Petrick JL, McGlynn KA and Bray F: Projections of primary liver cancer to 2030 in 30 countries worldwide. Hepatology 67: 2, 2017.

2. Tsai WC, Kung PT, Wang YH, Kuo WY and Li YH: Influence of the time interval from diagnosis to treatment on survival for early-stage liver cancer. PLoS One 13: e0199532, 2018.

3. Giunchi F, Vasuri F, Baldin P, Rosini F, Corti B and D'ErricoGrigioni A: Primary liver sarcomatous carcinoma: Report of two cases and review of the literature. Pathol Res Pract 209: 249-254, 2013.

4. Chuang SC, Lee YC, Hashibe M, Dai M, Zheng T and Boffetta P: Interaction between cigarette smoking and hepatitis B and $C$ virus infection on the risk of liver cancer: A meta-analysis. Cancer Epidemiol Biomarkers Prev 19: 1261-1268, 2010.

5. Romani S, Azimzadeh P, Mohebbi SR, Kazemian S, Almasi S, Naghoosi H, Derakhshan F and Zali MR: Investigation of transforming growth factor- $\beta 1$ gene polymorphisms among Iranian patients with chronic hepatitis C. Hepat Mon 11: 901-906, 2011.

6. Yao H, Chen H, Chen J, Zhu J and Zhang Y: Long-term survival trends for liver cancer in Qidong: 1972 to 2011. Zhonghua Gan Zang Bing Za Zhi 22: 921-925, 2014 (In Chinese).

7. Barranger E, Cortez A, Uzan S, Callard P and Darai E: Value of intraoperative imprint cytology of sentinel nodes in patients with cervical cancer. Gynecol Oncol 94: 175-180, 2004.

8. Zheng R, Zuo T, Zeng H, Zhang S and Chen W: Mortality and survival analysis of liver cancer in China. Zhonghua Zhong Liu Za Zhi 37: 697-702, 2015 (In Chinese).

9. Finnson KW, Arany PR and Philip A: Transforming growth factor beta signaling in cutaneous wound healing: Lessons learned from animal studies. Adv Wound Care (New Rochelle) 2: 225-237, 2013.

10. Ahn YO, Lee JC, Sung MW and Heo DS: Presence of membranebound TGF-beta1 and its regulation by IL-2-activated immune cell-derived IFN-gamma in head and neck squamous cell carcinoma cell lines. J Immunol 182: 6114-6120, 2009.

11. Fu BH, Fu ZZ, Meng W, Gu T, Sun XD and Zhang Z: Platelet VEGF and serum TGF- $\beta 1$ levels predict chemotherapy response in non-small cell lung cancer patients. Tumour Biol 36: 6477-6483, 2015. 
12. Dumitrescu CI, Gheonea IA, Săndulescu L, Surlin V, Săftoiu A and Dumitrescu D: Contrast enhanced ultrasound and magnetic resonance imaging in hepatocellular carcinoma diagnosis. Med Ultrason 15: 261-267, 2013

13. Noebauer-Huhmann IM, Szomolanyi P, Kronnerwetter C Widhalm G, Weber M, Nemec S, Juras V, Ladd ME, Prayer D and Trattnig S: Brain tumours at 7T MRI compared to 3T contrast effect after half and full standard contrast agent dose: Initial results. Eur Radiol 25: 106-112, 2015.

14. Regan F, Beall DP, Bohlman ME, Khazan R, Sufi A and Schaefer DC: Fast MR imaging and the detection of small-bowel obstruction. AJR Am J Roentgenol 170: 1465-1469, 1998.

15. Patel V, Chityala RN, Hoffmann KR, Ionita CN, Bednarek DR and Rudin S: Self-calibration of a cone-beam micro-CT system. Med Phys 36: 48-58, 2009.

16. Fujimoto S, Giannopoulos AA, Kumamaru KK, Matsumori R, Tang A, Kato E, Kawaguchi Y, Takamura K, Miyauchi K, Daida $\mathrm{H}$, et al: The transluminal attenuation gradient in coronary CT angiography for the detection of hemodynamically significant disease: Can all arteries be treated equally? Br J Radiol 91: 20180043, 2018

17. Cui HZ, Dai GH, Shi Y and Chen L: Sorafenib combined with TACE in advanced primary hepatocellular carcinoma. Hepatogastroenterology 60: 305-310, 2013.

18. Chung KY and Kemeny N: Regional and systemic chemotherapy for primary hepatobiliary cancers and for colorectal cancer metastatic to the liver. Semin Radiat Oncol 15: 284-298, 2005.

19. Nderitu P, Bosco C, Garmo H, Holmberg L, Malmström H, Hammar N, Walldius G, Jungner I, Ross P and Van Hemelrijck M: The association between individual metabolic syndrome components, primary liver cancer and cirrhosis: A study in the Swedish AMORIS cohort. Int J Cancer 141: 1148-1160, 2017.

20. Raju J and Bird RP: Differential modulation of transforming growth factor-betas and cyclooxygenases in the platelet lysates of male F344 rats by dietary lipids and piroxicam. Mol Cell Biochem 231: 139-146, 2002.

21. Kloen P, Gebhardt MC, Perez-Atayde A, Rosenberg AE, Springfield DS, Gold LI and Mankin HJ: Expression of transforming growth factor-beta (TGF-beta) isoforms in osteosarcomas: TGF-beta3 is related to disease progression. Cancer 80: 2230-2239, 1997.
22. Chen HY, Chen ZX, Huang RF, Lin N and Wang XZ: Hepatitis B virus $X$ protein activates human hepatic stellate cells through upregulating TGF $\beta 1$. Genet Mol Res 13: 8645-8656, 2014.

23. Dong YD, Cui L, Peng CH, Cheng DF, Han BS and Huang F: Expression and clinical significance of HMGB1 in human liver cancer: Knockdown inhibits tumor growth and metastasis in vitro and in vivo. Oncol Rep 29: 87-94, 2013.

24. Song BC, Chung YH, Kim JA, Choi WB, Suh DD, Pyo SI, Shin JW, Lee HC, Lee YS and Suh DJ: Transforming growth factor-beta1 as a useful serologic marker of small hepatocellular carcinoma. Cancer 94: 175-180, 2002.

25. Jain AR, Jain M, Kanthala AR, Damania D, Stead LG, Wang HZ and Jahromi BS: Association of CT perfusion parameters with hemorrhagic transformation in acute ischemic stroke. AJNR Am J Neuroradiol 34: 1895-1900, 2013.

26. Zhang Q, Zhang XL, Zhang YZ, Cheng GX and Chen ZQ: Hemodynamic study of primary hepatocellular carcinoma evolved from viral-induced cirrhosis using CT perfusion imaging. Nan Fang Yi Ke Da Xue Xue Bao 28: 1986-1989, 2008 (In Chinese).

27. Bilezikçi B, Haberal AN and Demirhan B: Hepatocyte growth factor in patients with three different stages of chronic liver disease including hepatocellular carcinoma, cirrhosis and chronic hepatitis: An immunohistochemical study. Can J Gastroenterol 15: 159-165, 2001.

28. Lu DD, Zhang XR and Cao XR: Expression and significance of new tumor suppressor gene PTEN in primary liver cancer. J Cell Mol Med 7: 67-71, 2003

29. Li JP, Feng GL, Li DQ, Wang HB, Zhao DL, Wan Y and Jiang HJ: Detection and differentiation of early hepatocellular carcinoma from cirrhosis using CT perfusion in a rat liver model. Hepatobiliary Pancreat Dis Int 15: 612-618, 2016.

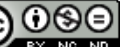

This work is licensed under a Creative Commons Attribution-NonCommercial-NoDerivatives 4.0 International (CC BY-NC-ND 4.0) License. 